\title{
Oviraptorosaur tail forms and functions
}

\author{
W. Scott Persons, IV, Philip J. Currie, and Mark A. Norell \\ Acta Palaeontologica Polonica 59 (3), 2014: 553-567 doi: http://dx.doi.org/10.4202/app.2012.0093
}

Oviraptorosaur caudal osteology is unique among theropods and is characterized by posteriorly persistent and exceptionally wide transverse processes, anteroposteriorly short centra, and a high degree of flexibility across the pre-pygostyle vertebral series. Three-dimensional digital muscle reconstructions reveal that, while oviraptorosaur tails were reduced in length relative to the tails of other theropods, they were muscularly robust. Despite overall caudal length reduction, the relative size of the $\mathrm{M}$. caudofemoralis in most oviraptorosaurs was comparable with those of other non-avian theropods. The discovery of a second Nomingia specimen with a pygostyle confirms that the fused terminal vertebrae of the type specimen were not an abnormality. New evidence shows that pygostyles were also present in the oviraptorosaurs Citipati and Conchoraptor. Based on the observed osteological morphology and inferred muscle morphology, along with the recognition that many members of the group probably sported broad tail-feather fans, it is postulated that oviraptorosaur tails were uniquely adapted to serve as dynamic intraspecific display structures. Similarities, including a reduced vertebral series and a terminal pygostyle, between the tails of oviraptorosaurs and the tails of theropods widely accepted as basal members of the Avialae, appear to be convergences.

Key words: Dinosauria, Theropoda, Oviraptorosauria, pygostyle, caudal musculature, functional morphology.

W. Scott Persons, IV [persons@ualberta.ca] and Philip J. Currie [philip.currie@ualberta.ca ], University of Alberta, Department of Biological Sciences, Edmonton, Alberta, T6G2E9, Canada; Mark A. Norell [norell@amnh.org], American Museum of Natural History, New York City, New York, USA.

This is an open-access article distributed under the terms of the Creative Commons Attribution License (for details please see creativecommons.org), which permits unrestricted use, distribution, and reproduction in any medium, provided the original author and source are credited. 
For 5 Full text $(636.8 \mathrm{kB})$ ।

POFF' Supplementary file $(30.1 \mathrm{kB})$ 